\title{
Observations of the Temperature of the Surface of the Sea off Plymouth.
}

THe observations given below are by Mr. William Roach (Series I), Associate Member M. B. A., and by Mr. H. Roach (Series II), the fisherman of the Association. The observations are taken partly in Plymouth Sound and partly on the fishing grounds a few miles to the eastward. A careful comparison of the two sets during the same periods does not show any local differences, and as the observations are true sea temperatures throughout, it is unnecessary to state the positions more definitely.

It has been thought best to give the results in the form of ten-day means, as being most convenient for use in connection with fishery statistics.-H. N. Dickson.

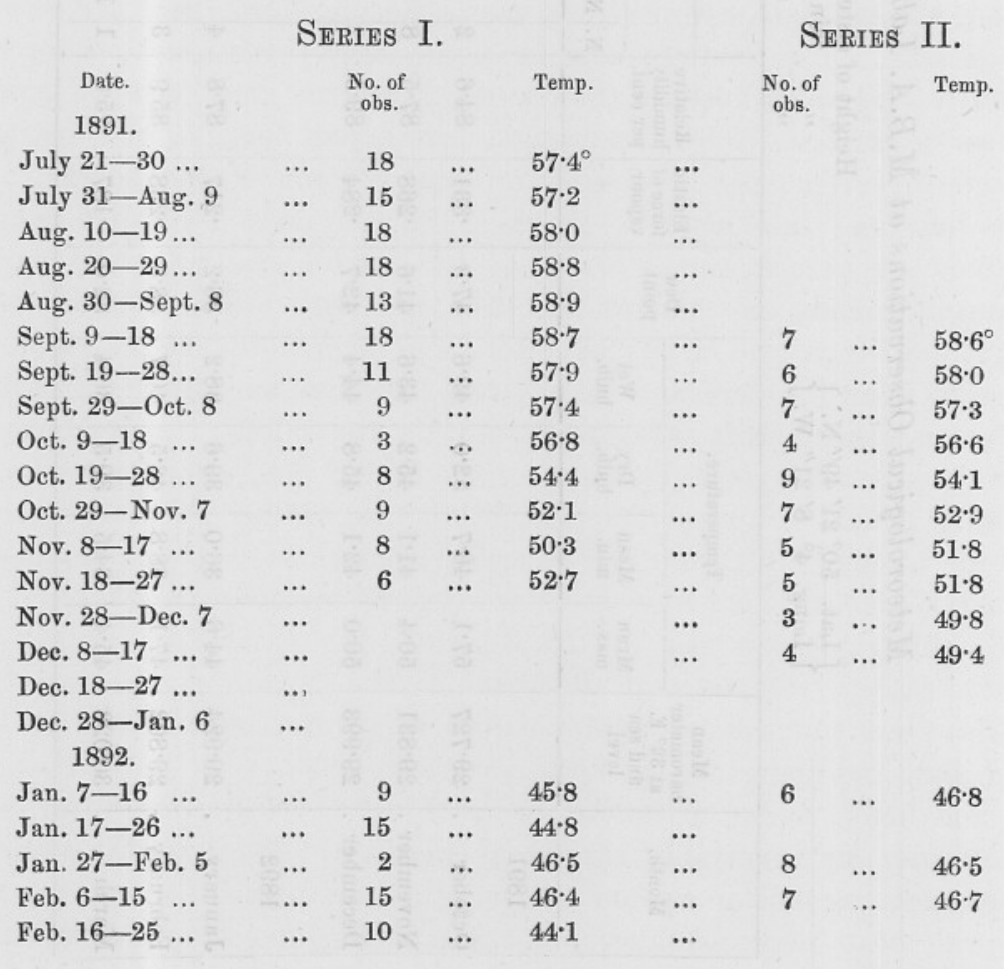

